\title{
THE STUDENT-INQUIRER IDENTITY DURING THE MASTER THESIS IN AN ONLINE UNIVERSITY
}

\author{
Angelos Konstantinidis, Antoni Badia, Universitat Oberta de Catalunya, Spain
}

\section{Abstract}

When students are conducting their research project as part of their studies, they can be better prepared for the societal and professional challenges of the future. This study contributes to the research of the inquirer identity by elaborating a model for the assessment of student-inquirer identity skills in light of the development of a master thesis in an education-related field in an online university. The model presents student-inquirer identity as a dynamic multiplicity of ten skills related to the five phases of the practice of inquiry (search and focus, understand and explore, design and implement, interpret/evaluate and reflect, write and present). Based on the model, a questionnaire that measures students' inquiry skills during the development of the master thesis was constructed. The questionnaire is comprised of ten subscales with 42 Likert-type items in total. 154 students of the Universitat Oberta de Catalunya responded to the questionnaire. Findings revealed that, overall, online students develop inquiry skills to a moderate extent while conducting their master thesis.

\section{Introduction}

The last decade we have witnessed many tech-related trends that both increased the saturation of technologies in our daily life and raised several concerns as regards their (mis)use (Auxier et al., 2019). While more than half of the population owns a smartphone and has internet access even in the developing world (Poushter et al., 2018), a growing number of people are becoming ambivalent about the impact of digital connectivity on society as a whole (Smith, 2018). In this period of crisis, professionals upon graduating from the university must have the skills, attitudes, and stances that will enable them to address the challenges of the digital world.

Whereas there is no magic therapy that alleviates the problems of digitisation, developing an inquirer identity to students and teachers has been recognised fundamental for the society and school of the future (Alvunger \& Wahlström, 2017; Meijer et al., 2016; Taylor, 2017). Nevertheless, although inquiry as a concept and practice in education is nearly one 
century old dating back to the work of John Dewey, there is lack of a clear and empirically grounded definition of inquiry-based attitude (Meijer et al., 2016), while the research on inquirer identity is scarce, to say at least (Badia et al., 2020; Konstantinidis \& Badia, 2019; Taylor, 2017). More research on the inquirer identity would benefit the design and development of professional development courses aiming at nurturing and promoting inquiry attitudes and competencies (Badia et al., 2020).

This study aims to contribute to the research towards the development of a well-structured definition of the notion of inquirer identity, applied to both students and teachers. In line with Oyserman et al. (2012) we perceive that identities include the personal traits and characteristics as well as one's social relations, roles, and memberships. Accordingly, the inquirer identity encompasses components related to the competencies, knowledge, actions, beliefs, and roles regarding inquiry (Badia et al., 2020).

This study is part of a larger research project entitled "The inquirer identity of teachers and student-teachers", and its overarching aim is to identify and characterise the identity components related to inquiry when teachers are involved in pedagogical innovations, as well as to categorise clusters of teachers which show different ways of positioning in light of pedagogical innovations. In particular, this study focuses on one component of the student-inquirer identity, the skills that students develop while doing their master thesis and elaborates a model and a questionnaire for assessing this component.

\section{Methodology}

\section{Construction of the student-inquirer identity model}

The structure of the student-inquirer model is primarily based on the teacher-inquirer identity model by Konstantinidis and Badia (2019). The teacher-inquirer identity consists of ten teacher skills which are related with the five phases of the inquiry process: scan and focus, understand and explore, plan and implement, evaluate and reflect, and write and present.

In order to adapt the teacher-inquirer identity model to the ways students conduct inquiry during their master thesis, we reviewed bibliography related to researching in social sciences (Bell \& Waters, 2014; Booth et al., 2016; Cohen et al., 2000). Although each author approaches the process of researching from a different angle and with a different audience in mind, we could see the five phases of the inquiry process emerging from the topics of each book, even if not in the same order necessarily. Therefore, we decided to maintain the five main phases and make only some changes. The resulted model is presented in Table 1. 
Konstantinidis, A., \& Badia, A.

The Student-Inquirer Identity during the Master Thesis in an Online University

Table 1: $\quad$ The inquiry phases and the skills that comprise the student-inquirer identity

\begin{tabular}{ll}
\hline Inquiry Phase & Skills \\
\hline Search and Focus & $\begin{array}{l}\text { Search for potential topics to develop the thesis } \\
\text { Focus on a particular topic to develop the thesis } \\
\text { Build knowledge and understanding on the topic (i.e. through } \\
\text { reading resources) } \\
\text { Explore what other people know about the topic } \\
\text { Design a thesis on the topic } \\
\text { Implement the research project/collect and analyse data }\end{array}$ \\
Design and Implement & $\begin{array}{l}\text { Interpret the results and evaluate the research project } \\
\text { Reflect on the process and outcomes } \\
\text { Interpret/Evaluate and }\end{array}$ \\
Reflect & $\begin{array}{l}\text { Write the thesis } \\
\text { Prite and Present the thesis to the committee }\end{array}$ \\
\hline
\end{tabular}

\section{Construction of a questionnaire for measuring students' inquiry skills}

Based on the model, we constructed a questionnaire that intends to measure the inquiry skills that students develop while they are conducting their master thesis. The questionnaire was constructed and refined through three stages. Initially, the first author crafted several question items for each one of the sub-identities related to the process of inquiry. Next, the second author reviewed the question items and added a few question items as well. Lastly, the final list of items was reviewed by both authors and any ambiguous item was discussed and subsequently rewritten or deleted.

The final questionnaire is comprised of ten sub-scales, with 42 Likert-type items in total and can be seen in Table 2. Each subscale corresponds to a specific skill of the studentinquirer identity. The response scale ranged from 1 to 5 (not at all, to a small extent, to some extent, to a moderate extent, to a great extent).

\section{Sample}

The questionnaire was sent to six cohorts of students (in total 1239 students) of three postgraduate programmes (education and ICT, psychopedagogy, and learning difficulties) who attended the TFM (master thesis project) at the Universitat Oberta de Catalunya (UOC) during academic years 2019-2020. The questionnaire was emailed a few days after the deadline for the presentation of their thesis to the committee and a reminder was sent a few weeks after the first email. In total 154 students responded to the questionnaire (response rate 12.4\%). Approximately four out of ten of the respondents are aged between $21-30(\mathrm{~N}=59 ; 38.3 \%)$ and another four out of ten $31-40(\mathrm{~N}=61 ; 39.6 \%)$. Nearly half of the respondents $(\mathrm{N}=70 ; 45.5 \%)$ were working in formal education as primary or secondary school teachers, nursery and kindergarten teachers, special education teachers, and secondary school teachers. The vast majority of the respondents $(\mathrm{N}=144 ; 93.5 \%)$ have working experience and/or they are currently working, while, on average, respondents have nearly ten years of working experience. Over four out of ten of the respondents $(\mathrm{N}=66 ; 44.7 \%)$ reported advanced or higher English language level, four out of ten 
intermediate $(\mathrm{N}=62 ; 40.3 \%)$, and less than one-fifth elementary or lower $(\mathrm{N}=26 ; 16.9 \%)$. As regards their experience in doing work related to a master thesis, nearly half of the respondents $(\mathrm{N}=69 ; 44.8 \%)$ had completed an undergraduate thesis and another one out of five a graduate thesis $(\mathrm{N}=28 ; 18.2 \%)$, while less than one-fifth of the respondents $(\mathrm{N}=23 ; 14.9 \%)$ reported having no previous experience in doing activities similar to those requested in a TFM. Lastly, as regards the type of the thesis, half of the respondents conducted empirical research or intervention research $(\mathrm{N}=80 ; 51.9 \%)$ and more than four out of ten of the respondents $(\mathrm{N}=66 ; 42.9 \%)$ conducted an educational intervention related to their profession.

\section{Results}

\section{Students' inquiry skills while conducting the master thesis}

Respondents' answers to the questionnaire show that online students develop inquiry skills to a moderate extent while conducting their postgraduate thesis. In the following subsections respondents' answers to the questionnaire will be analysed in greater detail while Table 2 reports the mean and SD of responses for each question item and each subscale.

\section{Searching}

Students reported the development of searching skills to a moderate extent before actually start working on their research project (mean: 4.16; SD: .67). They seem a bit more inclined to search for potential topics through browsing related websites (mean: 4.32) and the literature (mean: 4.30) rather than asking the opinion of others (mean: 4.03) or making a list of their interests (mean: 4.00).

\section{Focusing}

Students reported that they develop skills related with focusing on a topic they recognised during the searching process to a moderate extent (mean: 4.07; SD: .69). Although the difference among the means of the particular set of skills is low overall, it seems that respondents are more inclined to develop skills related with identifying the purpose of their thesis (mean: 4.23), next formulating relevant research questions (mean: 4.11), following that reducing the list of topics (mean: 4.00), and to a lesser extent evaluating the viability of the thesis on the chosen topic (mean: 3.94 ).

\section{Understanding}

Students reported that they develop skills related with building knowledge and understanding of the topic at hand to a moderate extent (mean: 4.17; SD: .68). The difference among the means of the particular set of skills is low overall. However, respondents engage with skills related with reading the literature to a greater extent (mean: 
4.28), next conducting an organised search to find key literature on the topic (mean: 4.19) and recording and organising the information related to the topic (mean: 4.18), and lastly evaluating the literature found for quality and relevance (mean: 4.01).

\section{Exploring}

Students reported that they develop skills related with exploration about a topic to some extent (mean: 2.99; SD: 1.13). To a considerably greater extent, they are asking more knowledgeable others about the topic (mean: 3.49) and they are discussing their topics with their colleagues (mean: 3.28). Conversely, they are engaged to a lesser extent with attending learning events about the topic (mean: 2.65) or posting questions about the topic on the internet (mean: 2.55).

\section{Designing}

Students reported that they develop skills related with the designing of their master thesis to a moderate extent (mean: 4.00; SD: .83). Writing the theoretical part of the thesis was the skill that students developed more (mean: 4.29) followed by the consideration of the ethical issues (mean: 4.18). Following that, they are engaged to a similar extent with selecting the research methodology (mean: 4.05) and selecting or designing the data collection methods and instruments (mean: 3.99). To a lesser extent they are engaged with the specification in an operational way of the aims (mean: 3.82) and utilisation of the data analysis methods (mean: 3.67 ).

\section{Implementing}

Students reported that they develop skills related with the implementation of their thesis to a moderate extent (mean: 3.97; SD: .96). There is little variation among the means of the specific skills: analysing collected data (4.03), collecting data (4.01), presenting the results in different ways (3.96), and planning the fieldwork (3.89).

\section{Interpreting and Evaluating}

Students reported that they develop skills related with the interpretation of the results and evaluation of the outcomes to a moderate extent (mean: 4.17; SD: .70). There is almost no variation among the means in this set of skills: evaluating the results and reaching conclusions (4.23), evaluating the extent to which the thesis has achieved its initial purpose (4.18), interpreting and discussing the results (4.11).

\section{Reflecting}

Students reported that they develop skills related with reflection to a moderate extent (mean: 3.97; SD: .82). The responses reveal that students are a bit more inclined to reflect on the adequacy of the research methodology and the relevance of the results (mean: 4.02) and to a lesser extent to reflect on the implementation of the project (mean: 3.88 ). 


\section{Writing}

Students reported that they develop skills related to writing their thesis to a moderate extent (mean: 4.22; SD: .76). When looking more closely the means of this set of skills, it becomes clear that students' engagement with writing skills is in general well above moderate: writing all the necessary parts of the thesis (4.54), structuring the thesis (4.41), using a citation style consistently throughout the thesis (4.37), and self-evaluating the thesis before submission (4.34). However, when it comes to sending the final document to others for feedback, then respondents indicated that they develop this skill only to some extent (mean: 3.43).

\section{Presenting}

Students reported that they develop skills related to presenting their thesis to a moderate extent (mean: 4.32; SD: .79). Overall, there is little variation among the means of the specific set of skills, yet it seems that respondents worked more on skills related with the development of the presentation document (mean: 4.43) as well as with the presentation and recording (mean: 4.38) and answering board's questions about the presentation (mean: 4.40). To a bit lower extent, they were engaged with rehearsing and revising the presentation (mean: 4.28) and reflecting on the process of presenting the TFM (mean: 4.13).

Table 2: The questionnaire for measuring students' inquiry skills while conducting their master thesis and the mean and standard deviation of responses for each question item and each subscale.

\begin{tabular}{llr}
\hline & $M$ & SD \\
Searching & 4.16 & .67 \\
\hline 1. Listing relevant topics/interests to your profession or listing topics that you & 4.00 & .68 \\
would like to research & & \\
2. Asking the opinion of others (e.g. tutors, colleagues, peers, friends) about your & 4.03 & .83 \\
initial ideas & & \\
3. Browsing literature related to your field and/or your interests & 4.30 & .57 \\
4. Browsing websites related to your field and/or your interests & 4.32 & .60 \\
\hline Focusing & 4.07 & .69 \\
\hline 5. Reducing the list of topics to a choice of 2-3 topics & 4.00 & .83 \\
6. Identifying the purpose of your TFM & 4.23 & .61 \\
7. Formulating research questions or professional intervention questions about & 4.11 & .59 \\
the chosen topic & & \\
8. Evaluating the viability of the TFM on the chosen topic & 3.94 & .74 \\
\hline Understanding & 4.17 & .68 \\
\hline 9. Conducting an organised search to find key literature related to the topic & 4.19 & .71 \\
10. Evaluating literature found for quality and relevance with the topic & 4.01 & .76 \\
11. Reading literature to increase your knowledge on the topic & 4.28 & .62 \\
12. Recording and organising the information related to the topic & 4.18 & .64 \\
\hline Exploring & 2.99 & 1.13 \\
\hline 13. Discussing with your colleagues about the topic (e.g. with your classmates) & 3.28 & 1.14 \\
14. Posting questions about the topic on websites/social media & 2.55 & 1.07
\end{tabular}


15. Asking more knowledgeable others (e.g. academics, mentors/professionals) $\quad 3.49$

16. Attending face-to-face or online learning events (e.g. conferences) to learn $\quad 2.65$

about the topic

\begin{tabular}{|c|c|c|}
\hline Designing & 4.00 & .83 \\
\hline $\begin{array}{l}\text { 17. Specifying in an operational way the research aims or the aims of the } \\
\text { professional intervention }\end{array}$ & 3.82 & .87 \\
\hline 18. Considering the ethical issues & 4.18 & .87 \\
\hline $\begin{array}{l}\text { 19. Selecting the research methodology or the methodology of the professional } \\
\text { intervention }\end{array}$ & 4.05 & .80 \\
\hline 20. Designing and/or selecting the data collection methods and instruments & 3.99 & .84 \\
\hline 21. Utilising the data analysis methods & 3.67 & 1.03 \\
\hline 22. Writing the theoretical part of the TFM & 4.29 & .59 \\
\hline Implementing & 3.97 & .96 \\
\hline $\begin{array}{l}\text { 23. Planning the fieldwork (e.g. scheduling interviews, conducting a pilot, } \\
\text { selecting participants) }\end{array}$ & 3.89 & 1.03 \\
\hline 24. Collecting data of the research or the professional intervention & 4.01 & .93 \\
\hline 25. Analysing collected data & 4.03 & .86 \\
\hline 26. Presenting the results of the TFM in different ways (e.g. tables, graphs) & 3.96 & 1.00 \\
\hline Interpreting \& evaluating & 4.17 & .70 \\
\hline 27. Interpreting and discussing the results & 4.11 & .76 \\
\hline 28. Evaluating the results and reaching conclusions & 4.23 & .66 \\
\hline 29. Evaluating the extent to which the TFM has achieved its initial purpose & 4.18 & .67 \\
\hline Reflecting & 3.97 & .82 \\
\hline $\begin{array}{l}\text { 30. Reflecting on the adequacy of the design of the research/professional } \\
\text { intervention methodology }\end{array}$ & 4.02 & .78 \\
\hline $\begin{array}{l}\text { 31. Reflecting on the implementation of the research project or professional } \\
\text { intervention project }\end{array}$ & 3.88 & .89 \\
\hline $\begin{array}{l}\text { 32. Reflecting on the relevance of the results of the research or professional } \\
\text { intervention project }\end{array}$ & 4.02 & .80 \\
\hline ( & 4.22 & .76 \\
\hline 33. Structuring the TFM according to the guidelines & 4.41 & .62 \\
\hline 34. Writing all the required parts of the TFM & 4.54 & .57 \\
\hline $\begin{array}{l}\text { 35. Using a citation style throughout the TFM and verifying that the reference list } \\
\text { is correct }\end{array}$ & 4.37 & .70 \\
\hline $\begin{array}{l}\text { 36. Sending the TFM document before submission to others (e.g. peers) and } \\
\text { asking for feedback }\end{array}$ & 3.43 & 1.20 \\
\hline 37. Self-evaluating the TFM before submission (e.g. revising and proofreading) & 4.34 & .69 \\
\hline Presenting & 4.32 & .79 \\
\hline 38. Developing a specific document (e.g. a PowerPoint) to present the TFM & 4.43 & .70 \\
\hline 39. Rehearsing and revising the presentation & 4.28 & .82 \\
\hline 40. Presenting and recording the presentation of the TFM & 4.38 & .77 \\
\hline 41. Answering the board's questions about the presentation & 4.40 & .71 \\
\hline 42. Reflecting on the process of presenting the TFM to the board & 4.13 & .95 \\
\hline
\end{tabular}

\section{Conclusions}

\section{The design of the student-inquirer identity model and the questionnaire}

This study built on the teacher-inquirer identity model to construct a model for the student identity as an inquirer. The model presents the student-inquirer identity as a dynamic 
multiplicity of ten skills related to the five phases of the practice of inquiry. The results of the questionnaire corroborate to a considerable extent the validity of our model.

Based on the student-inquirer identity model, we constructed a quantitative questionnaire that seeks to measure the development of students' inquiry skills while they are conducting their master thesis. Admittedly, the questionnaire adopts a quite narrow perspective in identifying the inquiry skills both due to its nature (quantitative), but also because in our efforts to present a short and as simple as possible questionnaire we included only issues related with the process of inquiry during the master thesis. As a result, the questionnaire in its current form largely ignores the inquiry context (i.e. students' interests or work) as well as students' personal characteristics (i.e. beliefs about inquiry, relationships, agency, etc.). This limitation should be taken into account for the interpretation of the results. Nevertheless, the results show that the question items are highly relevant to the inquiry skills that it intends to measure.

\section{Students' inquiry skills while conducting the master thesis}

The results show that, in general, when students develop their master thesis as part of their studies in an education-related field in an online university, they develop inquiry skills. More specifically, they develop searching, focusing, understanding, designing, implementing, interpreting and evaluating, reflecting, writing, and presenting skills to a moderate extent and exploring skills to some extent. While it is difficult based only on these quantitative data to explain the small differences observed among the calculated means, it seems that students develop and work more on some skills than others. Whether this is a necessity (i.e. some skills are needed more or are more relevant for conducting the thesis), personal choice (i.e. they might feel that they need to advance their skills in some areas more compared to others), or whether there are other underlying reasons needs to be further investigated through qualitative studies. What is more important, however, is that the proposed student-inquirer identity model, which identifies five phases of inquiry is affirmed to a considerable extent by the results of the questionnaire.

\section{References}

Alvunger, D., \& Wahlström, N. (2017). Research-based teacher education? Exploring the meaning potentials of Swedish teacher education. Teachers and Teaching, 24(4), 1-18. https://doi.org/10.1080/13540602.2017.1403315

Auxier, B., Anderson, M., \& Kumar, M. (2019, December 20). 10 tech-related trends that shaped the decade. Pew Research Center [Blog post]. https://www.pewresearch.org/fact-tank/2019/12/20/10-tech-related-trends-thatshaped-the-decade/ 
Badia, A., Liesa, E., Becerril, L., \& Mayoral, P. (2020). A dialogical self approach to the conceptualisation of teacher-inquirer identity. European Journal of Psychology of Education. https://doi.org/10.1007/s10212-019-00459-z

Bell, J., \& Waters, S. (2014). Doing your research project: A guide for first time researchers.

Booth, W. C., Colomb, G. G., Williams, J. M., Bizup, J., \& FitzGerald, W. T. (2016). The Craft of Research ( $4^{\text {th }}$ ed.). University of Chicago Press.

Cohen, L., Manion, L., \& Morrison, K. (2000). Research methods in education ( $5^{\text {th }}$ ed.). RoutledgeFalmer.

Konstantinidis, A., \& Badia, A. (2019). Inquirer Teacher Identity during an Educational Innovation. ICERI2019, 5126-5134.

Meijer, M.-J., Geijsel, F., Kuijpers, M., Boei, F., \& Vrieling, E. (2016). Exploring teachers' inquiry-based attitude. Teaching in Higher Education, 21(1), 64-78. https://doi.org/10.1080/13562517.2015.1115970

Oyserman, D., Elmore, K., \& Smith, G. (2012). Self, Self-Concept, and Identity. In M. R. Leary \& J. P. Tangney (Eds.), Handbook of self and identity ( $2^{\text {nd }}$ ed, pp. 69-104). Guilford Press.

Poushter, J., Bishop, C., \& Chwe, H. (2018, June 19). Social Media Use Continues to Rise in Developing Countries but Plateaus Across Developed Ones. Pew Research Center [Blog post]. https://www.pewresearch.org/global/2018/06/19/social-media-usecontinues-to-rise-in-developing-countries-but-plateaus-across-developed-ones/

Smith, A. (2018, April 30). Declining Majority of Online Adults Say the Internet Has Been Good for Society. Pew Research Center [Blog post]. https://www.pewresearch.org/internet/2018/04/30/declining-majority-of-onlineadults-say-the-internet-has-been-good-for-society/

Taylor, L. A. (2017). How teachers become teacher researchers: Narrative as a tool for teacher identity construction. Teaching and Teacher Education, 61, 16-25. https://doi.org/10.1016/j.tate.2016.09.008

\section{Acknowledgements}

This research is conducted with the support of a doctoral grant from the UOC. 